\title{
Production and Management of Energy: The Interdisciplinary Approach of ENEA to Concentrated Solar Power
}

\author{
Domenico De Martinis $^{1, *}$ and Alberto Giaconia ${ }^{2, \S}$ \\ ENEA Italian National Agency for New Technologies, Energy and Sustainable \\ Economic Development \\ 1 International Relations Unit \\ 2 Thermal and Thermodynamic Solar Division \\ * current address: \\ Ministry of Education, University and Research -MIUR- Department for Higher \\ Education and Research \\ DG coordination, promotion and valorisation of research \\ National Office for the Planning and Promotion of Italian Research in \\ International spheres \\ $\S$ corrisponding author: alberto.giaconia@enea.it
}

\begin{abstract}
Clean and efficient energy generation by environmental friendly methods and technologies is now one of the major challenges worldwide. New and heterogeneous methods to produce energy pose the challenge of how to guarantee energy security, storage of exceeding production and distribution. In addition to that, the exploitation of next generation energy sources must consider the impact it may have on other productive systems and on rural areas (e.g. solar vs agriculture, biomass vs food production). ENEA has got and follows an interdisciplinary approach to "challenge the challenge" of a sustainable energy production, merging together materials science, agronomy and biotechnology, solar energy studies, energy efficiency management and more, in collaboration with industries and often in collaboration with the other stakeholders in the Mediterranean area. This paper describes the state of the art technology and how concentrating solar power (CSP) technology could be modulated to meet different energy needs, both spatial needs (e.g. off grid use vs dispatchability) and temporal needs (day vs night and energy on demand).
\end{abstract}

Keywords - Concentrating Solar Power ;CSP; Solar Energy; Renewable Energy; Energy Security; Mediterranean; Italy; Egypt; EU; Engineering; Solar Plans; Nanomaterials; Materials Science; Energy; Efficiency;Industry

\section{INTRODUCTION}

\section{- setting the scene}

The conversion of the energy system to a new one which maximizes the use of renewable energy sources as alternative to fossil fuels is a major objective effecting science, technology and policy choices nowadays. Yet, despite the global political will of exploiting clean and sustainable energy sources, the energy conversion depends on energy price market since few countries and their citizens in general are willing to bear production costs for the sake of an environmental friendly label ${ }^{1}$. Thus, performance and availability of the energy sources in terms of costs and security represent a must to ensure the appropriate penetration of any kind of energy source ${ }^{2}$. To date, $19.2 \%$ of global energy consumption is fuelled by renewables ${ }^{3}$, and renewable energy could represent the fastest growing power source over the next decades ${ }^{4}$; however, limits and challenges of such new age of energy generation must be considered, such as cost and security as already mentioned, but also distribution, storage and often complementarity with existing production and consumption systems and compatibility with future ones.

Among renewable energy approaches, concentrating solar power (CSP) holds a significant promise for adoption as an utility-scale. Different from many other direct renewable 
technologies, by the use of cost-effective thermal energy storage, CSP is easily dispatchable, and exhibits versatility in its output capability (heat, steam, chemical energy, mechanical work, or electric power). Additionally, CSP enables integration with conventional power stations, by producing steam with quality standards to drive a conventional turbine ${ }^{5}$. In a nutshell the technology enables to capture the solar heat by using mirrors or lenses to concentrate the sun rays captured on a wide area onto a much smaller surface like a Solar receiver tube with high photothermal efficiency and mechanical reliability to produce high temperature heat, similar to the heat recovered from traditional fuel combustion. As a result, the same technology usually applied for thermal conversion processes (e.g. steam turbines) can be applied for several energy applications (e.g. electrical power production). A conceptual scheme of the CSP basic components is represented in Fig. 1.

\section{The CSP Technology}

A CSP plant is basically composed of a "solar field", i.e. a large area covered with a number of solar collectors, each made of a supporting structure (anchored to the ground) for reflective panels (mirrors) and a solar tracking drive to continuously move and orient the mirrors in the direct normal ray direction.

The shape and orientation of the mirrors in the solar field allow focusing the solar rays captured by the reflective panels on the surface of the so-called "solar-receiver". The ratio between the overall mirrors' area and the solar receiver area represents a measure of the number of times the solar radiation is concentrated: depending on the CSP technology and application, the solar radiation is generally concentrated from tens to thousands times.

Clearly, for a given solar field and a receiver configuration, the effective captured heat flux depends on the overall efficiency which, in turn, depends on several efficiency factors like optical efficiency, tracking efficiency, mirrors' reflectance and cleanness, receiver's efficiency, etc. All these efficiency factors must be optimized in order to get the best overall performance of the CSP pant (e.g. annual production).

A "heat transfer fluid" (HTF) flows inside the solar receiver to remove the high-temperature heat from the receiver and transfers it, through a specific piping system, to the final heat loads and users. Depending on the CSP technology and conversion process requirements, the HTF can be pressurized water/steam, gas, oil, or molten salts.

At the end of the cycle, the HTF transfers its heat directly to the heat load, such as a steam generator for the production of super-saturated steam to drive a turbine in a Rankine cycle for electrical power production. Alternatively, the high-temperature heat can be used to drive purely thermal duties, like industrial thermochemical conversion reactors and processes for the production of the so-called "solar fuels". When the power load is lower than the available heat carried by the HTF, the excess heat is stored in a thermal energy storage (TES) system, to be used when necessary. After heat transfer to the thermal load(s), during hours with satisfactory direct solar radiation, the HTF is pumped to re-start the heat collection loop.

The solar field and the TES system can be integrated with a suitable "back-up" unit. The back-up unit is a device specifically designed to replace the solar field when the solar radiation is not adequate and the TES system is completely discharged, in order to sustain the heat demand (e.g. after extended cloudy periods). The back-up unit usually consists of a fuel combustor contributing to usually less than $10-15 \%$ of total energy production per year.

Clearly, the above mentioned elements and units comprising a CSP plant have to be operated using suitable control tools and procedures to maximize the solar power production and the security of power supply.

The development of the above mentioned units requires an extensive wide multi-disciplinary approach primarily aiming at innovation and the overall system improvement. This includes structural and mechanical engineering (e.g. for solar collectors and tracking drives), expertise in optics and materials coating (e.g. for efficiency improvements, qualification, reflective panels and solar-receivers development and maintenance), material science (e.g. for the heat transfer fluid and the TES), chemical engineering (for the thermochemical conversion), heat transfer skills (e.g. for the back-up unit, steam generator, etc.), hydraulics and fluid-dynamics (e.g. for the piping system), electronics skills (for the 
control and automation system), astronomical expertise (for the solar collectors' tracking system), etc.

ENEA's staff covers all the above mentioned expertise required for the full development of the CSP technology, from the individual components to the integrated plant design, construction and operation.

Concentrating solar technologies are divided in point and linear focusing systems. Point focusing systems include solar towers and parabolic dishes ${ }^{6}$. Linear CSP technologies are parabolic troughs or linear Fresnel reflectors which concentrate the solar radiation on receiver tubes. Since the '80s several hundred MW have been installed worldwide mainly in parabolic trough CSP plants typically using thermal oil HTF up to $400^{\circ} \mathrm{C}$ and a two-tank TES using molten salts as heat storage medium operating in the temperature range between $290^{\circ} \mathrm{C}$ and $380^{\circ} \mathrm{C}$. More recently, large solar tower CSP plants have been installed, commonly with direct heating of molten salts up to $565^{\circ} \mathrm{C}$ : thus, compared to traditional parabolic trough CSP plants typically using thermal oil HTF up to $400^{\circ} \mathrm{C}$, the overall efficiency of the conversion process in tower plants with direct molten salts is increased by increasing the upper temperature of the power cycle.

Since 2001 ENEA has developed a new CSP concept which benefits of the main advantages of solar troughs and tower systems: solar parabolic troughs are applied for the direct use of molten salts as HTF and TES medium up to $550^{\circ} \mathrm{C}$. This development was made possible by the above mentioned wide interdisciplinary potentials of ENEA in applied research. Hence, each component has been individually developed in laboratory and then tested in a prototype test plant at ENEA-Casaccia (Fig. 2).

After performance assessment and qualification, the developed components are made ready for replication in CSP plants on the demonstration and commercial scale. The first commercial- size plant (5 MW electrical) has been commissioned in 2010 in Sicily.

Based on the preliminary experience, in the forthcoming years ENEA's research on concentrating solar technology has been focused on further improvements of the technology with respect to individual components, plant integration, process optimization and new application scenarios. Fig. 3 represents a general process scheme conceived by ENEA for the application of this concentrating solar technology to heat and power production. Accordingly, the HTF consisting of a molten salts mixture (usually the binary mixture $\mathrm{NaNO}_{3} / \mathrm{KNO}_{3}$ $60 \%$ wt $/ 40 \%$ wt, though different formulation are under investigation) in the solar field is heated from about $290^{\circ} \mathrm{C}$ up to $550^{\circ} \mathrm{C}$ and then stored in a thermal energy storage tank to be used for different applications: steam generation, electrical power production,

thermochemical conversion and residual heat for heating/cooling of buildings or sea water desalination; in Fig. 3 a biomass-based back-up unit integrated in the plant scheme is also shown.

\section{Current Projects and Future Studies on CSP}

The CSP technology can be considered a mature technology for the market and, besides public research, several initiatives are on-going worldwide? ${ }^{7}$.

Therefore, the value of the approach is not questionable, but since the start of manufacturing plans the challenge is now how to improve the performance in different terms: construction costs, economy of production, training, easiness of use, flexibility of the system and integration with traditional and new technologies. Alternative molten salts mixture is under investigation at ENEA to ease operation and management of the plant (e.g. lower melting temperature). The molten salts at $550^{\circ} \mathrm{C}$ are collected in a storage tank. ENEA has conceived an innovative TES system based on a single tank directly integrated with the steam generator, as represented in Fig. 3. Moreover, CSP technology results in many products at different stages towards energy production (Fig. 3) that could be used alternatively; the first product of solar concentration is heat, namely concentrated solar thermal (CST) energy that could be either stored or used for those industrial processes that traditionally need to burn a fuel (the explanatory case of methane steam reforming is shown in Fig. 3). This use would lead to the deployment of greener industrial plants where combustion driven facilities, chimneys and combustion products would be minimized. Therefore, the produced heat at $550^{\circ} \mathrm{C}$ can then be used to power a heat demanding thermochemical process like steam reforming and/or the produced steam used for electrical power production in a steam Rankine cycle (Fig. 3) for power generation to feed the electric grid or used 
locally (e.g. off-grid networks). Finally, residual heat can be used for district heating and cooling or for sea water desalination, a by-product which represents an extremely high added value to the process ${ }^{8}$. When the solar radiation is not adequate to heat the molten salts up to $550^{\circ} \mathrm{C}$, a molten salts heater is applied; this back-up unit can be fed by waste biomassderived fuels in order to obtain a $100 \%$ renewable energy conversion process to satisfy the heat and power demand with high flexibility. Such energy conversion schemes based on CSP are developed by ENEA in the framework of national and international projects. Among these are the projects MATS $^{9}$ (power, heating/cooling and desalination from a CSP plant based on ENEA's technology) and CoMETHy ${ }^{10}$ (steam reforming assisted by solar molten salts at $550^{\circ} \mathrm{C}$ ). Specifically, in MATS (Multipurpose Application by Thermodynamic Solar) a plant with the specifications reported in Table 1 is developed, built and demonstrated in the City of Borg El Arab (Egypt). In CoMETHy a molten salts heated steam reforming technology for hydrogen production has been developed and successfully proved with a pilot plant at ENEA-Casaccia research centre in Rome.

Table 1. Main Features of MATS Plant Built as in Borg El-Arab, Egypt.

\begin{tabular}{|c|c|c|}
\hline \multirow[t]{2}{*}{ Solar Field } & Type & $\begin{array}{c}\text { Linear Parabolic } \\
\text { Collectors (Solar } \\
\text { Trough) }\end{array}$ \\
\hline & Size & $\begin{array}{c}\text { ca. } 10,000 \mathrm{~m}^{2} \text { active } \\
\text { mirrors' surface }\end{array}$ \\
\hline \multirow{2}{*}{$\begin{array}{l}\text { Thermal } \\
\text { Energy } \\
\text { Storage }\end{array}$} & Type & $\begin{array}{c}\text { Single Tank } \\
\text { integrated with Steam } \\
\text { Generator }\end{array}$ \\
\hline & Size & $\begin{array}{c}\text { ca. } 14 \mathrm{MWh} \\
\text { (thermal), equivalent } \\
\text { ca. } 4 \text { hours }\end{array}$ \\
\hline \multirow[t]{2}{*}{ Back-up unit } & Type & Gas burner \\
\hline & Size & ca. 2.3 MW thermal \\
\hline \multirow[b]{2}{*}{$\begin{array}{c}\text { Electric } \\
\text { Power Unit }\end{array}$} & Type & Steam Rankine Cycle \\
\hline & Power & 1.0 MWe \\
\hline \multirow{2}{*}{$\begin{array}{l}\text { Desalting } \\
\text { Unit }\end{array}$} & Type & $\begin{array}{l}\text { MED: Multi-Effect } \\
\text { Desalinator }\end{array}$ \\
\hline & Capacity & $250 \mathrm{~m}^{3}$ per day \\
\hline
\end{tabular}

\section{Technological Transfer and Social Impact of Industrial CSP}

Technological transfer to industry is a key moment to ensure that the performance obtained at the research and development stage can be translated in cost effective/efficient energy production.
As mentioned in the previous section, ENEA was the first organization in the world that developed to the prototype and commercial level (12.5 MW thermal, about $5 \mathrm{MW}$ electrical equivalent) the linear focusing CSP technology with solar salts HTF (up to $550^{\circ} \mathrm{C}$ ) ${ }^{11}$. This process lasted about a decade (Fig. 4) and requested a role of the government, in fostering the public research into CSP, from project start-up to prototyping and an industrial role, that involved both the manufacturers and the distributor of energy and resulted in the construction of a demonstrative plan ${ }^{12}$. This "best practice" enabled the creation of a complete new high technology manufacture plant and merged together inter-disciplinary public research, component manufacturing and energy production and dispatch actors. To date, industry is fostering CSP technology in Italy and worldwide ${ }^{13,14}$, and the forecast is that CSP will contribute to global energy production with $90 \mathrm{GW}$ (worst scenario ${ }^{15}$ ) to $266 \mathrm{GW}$ (best scenario ${ }^{16}$ ) by 2030 and for a total share of about $28 \%$ of all renewable generation by 2060 (the highest growth potential $\left.{ }^{10}\right)$. The path therefore seems to be defined, and future challenges will focus on increasing the technological and economical value of the system.

The social impact of investing in CSP must not be underestimated when capacity is built in countries that are growing in demographical and/or economical terms; in short, the realization of e.g. $50 \mathrm{MW}$ with thermal storage system would employ about 1,500 people during the construction phase of the components and construction of the plant (about 2-3 years). To this figure, 50 permanent jobs must be considered for the management and maintenance of the power station. Moreover, it is worth to underline that about $65 \%$ of the new jobs would be located in the regions where the plants will be located $17,18,19,20$.

\section{CSP as Example of Technology Integration and the Role in the Smart Energy Generation and Management}

A sustainable energy production is globally considered a core objective in a historical moment of demographic growth, increasing welfare trends and environmental problems. The simple paradigm "increased population/decreased sources" is nowadays more articulated and solutions must match apparently opposite needs, such as the urbanization and the need of cultivated land, the change in population composition (e.g. the ageing 
society) and the different diets in different parts of the society around the globe 21,22 .

Generation and management of renewable energy implies several technological challenges at input and output levels; energy may be generated by different sources and at different times, and enter the electric distribution grid in different places. While renewable energy systems are capable of powering houses and small businesses without any connection to the electrical grid, any excess electricity production shall be stored. These aspects, if one considers the electric grid as traditionally conceived, are revolutionary. Thus, transition to renewable energies poses various levels of technological complexity.

Concentrated Solar Power is a key technology that solves many of the issues mentioned above; the flexibility of the system is important also in terms of societal impact, as the possibility to work in different scenarios and deliver different products may provide answers to the different needs; to make a specific example, in Sub-Saharan Africa (SSA) unreliable power supply poses a major impediment to reduce extreme poverty and boost shared prosperity. "Low density/Long Distance" human settlements and rural areas are lacking access to the grid and this makes costly the distribution of electrical power. This results in poor quality, environmental unfriendly and often unhealthy systems to produce power, that could be overcome if off-grid energy is locally provided 23 ; this issue can be solved by the introduction of small CSP plants with single-tank thermal energy storage systems like the one shown in Fig. 3, which could feed small communities with local "mini" distribution grids, together with the production of desalted water and other co-generation services (e.g. heating and cooling of buildings).

ENEA is the first organization in the world that developed to the prototype and commercial level an high performance $\left(550^{\circ} \mathrm{C}\right)$ linear focusing CSP technology and is now implementing alternative applications of these technologies; this implies a strong interdisciplinary approach of far related disciplines, from material science and nanotechnology to engineering and ICT to energy management, smart grid concept, climatology, agronomy, etc. All together, this is needed to create the know-how for an efficient use of energy, which would complement CSP with other generations system (e.g. biomass and photovolatics) and should be embedded in the energy and social context of the region where it is implemented. A technology to deliver clean, sustainable energy, and with energy, information, education, health, food production, in industrialized areas as well as in small, isolated communities is the approach ENEA uses also in the framework of strong international cooperation and in collaboration with industries in order to avoid the risk of taking the technology development far away from the societal needs.

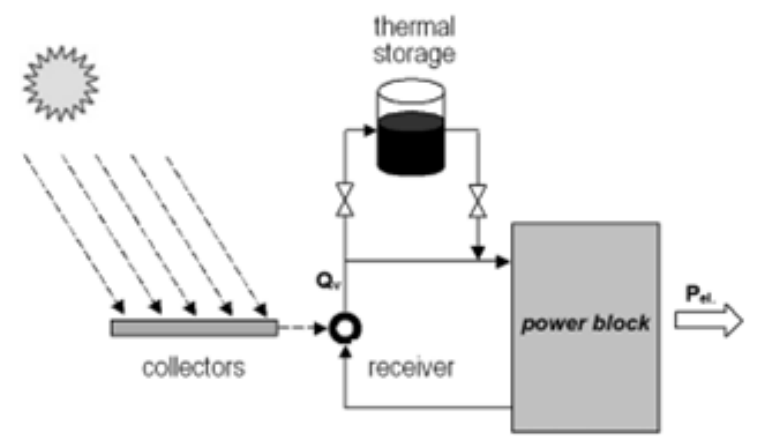

Fig .1. Conceptual scheme of the basic components of a CSP plant.

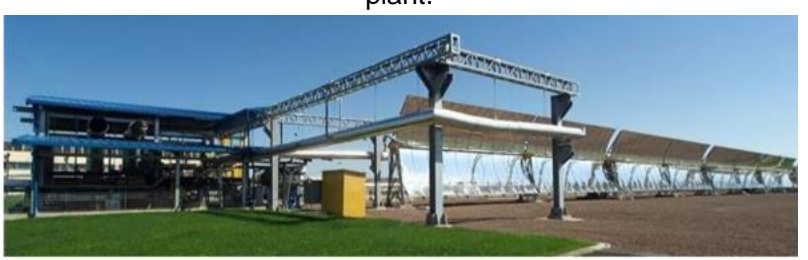

Fig .2. CSP components test plant at ENEA-Casaccia.

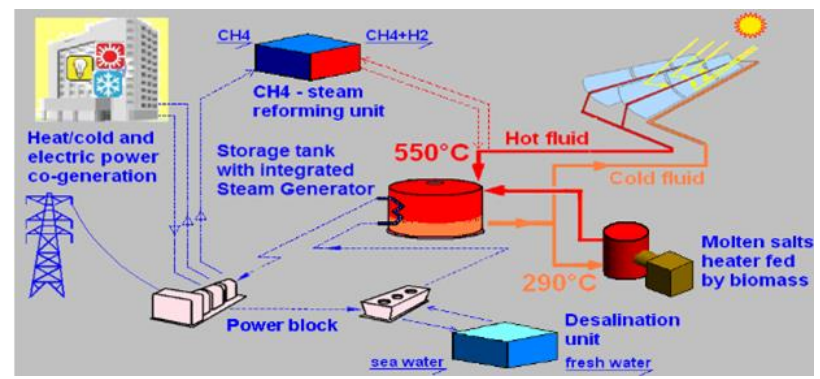

Fig .3. General process scheme of a co-generative CSP plant by ENEA.

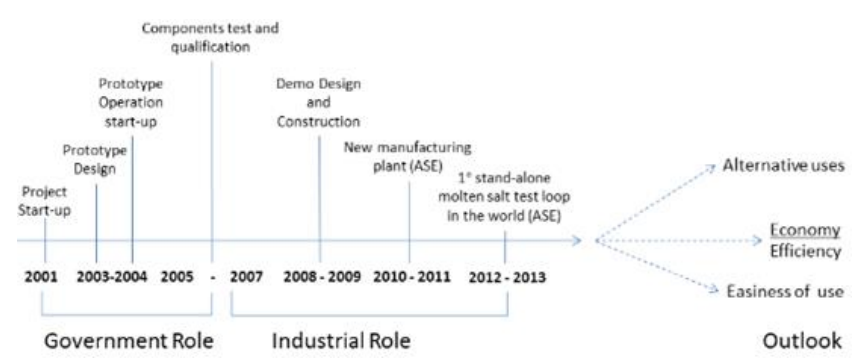

Fig .4. The basic step of the development of the CSP technology over time and future outlook. 


\section{REFERENCES}

[1] S. Osborne "Costa Rica powered by renewable energy for over 100 days."Independent . [On Line] Available: http://www.independent.co.uk/news/world/americ as/costa-rica-renewable-energy-100-days-powerclimate- change-a7217441.html [August., 2016].

[2] "Levelized cost and levelized avoided cost of new generation resources" Annual Energy Outlook 2016, U.S. Energy Information Administration (EIA). [On Line] Available: http://www.eia.gov/forecasts/aeo/pdf/electricity_g eneration.pdf [August 2016]

[3] REN21 "Renewables 2016 global status report," Paris: REN21 Secretariat. ISBN 978-3-98181070-7

Available: $\quad$ http://www.ren21.net/wpcontent/uploads/2016/06/GSR_2016_Full_Report .pdf [March 2016].

[4] B.Hulac. "Strong future forecast for renewable energy," Scientific American- Climate Wire

Available:

https://www.scientificamerican.com/article/strongfuture-forecast-for-renewable-energy/ [Apr. 27, 2015].

[5] M.T. Dunham and B.D. Iverson. "High-efficiency thermodynamic power cycles for concentrated solar power systems," Renewable and Sustainable Energy Reviews, vol. 30, pp 758770, 2014.

Available:

http://dx.doi.org/10.1016/j.rser.2013.11.010

[6] K. Lovengrove and W. Stein. (eds.). Concentrating solar power technology Principles, developments and applications. Woodhead Publishing Ltd., 2012. eBook ISBN: 9780857096173

[7] NREL National Renewable Energy Laboratories Concentrating Solar Power Projects

Available:

http://www.nrel.gov/csp/solarpaces/index.cfm.

[8] H. Hashem . "Can solar power produce freshwater in the Middle East? CSP Today," Available: http://social.csptoday.com/markets/can-solarpower-produce-freshwater-middle-east [Oct. 11, 2013].

[9] MATS Project (Multipurpose Applications by Thermodynamic Solar) Available: www.mats.enea.it [in progress].

[10] "Compact multifuel-energy to hydrogen converter project,"

Available:

http://cordis.europa.eu/result/rcn/144091_en.html [in progress].

[11] "Archimede solar energy (ASE),"

Available:

http://www.archimedesolarenergy.it/index.htm [in progress].

[12] "Archimede solar power plant," Wikipedia Available:https://en.wikipedia.org/wiki/Archimede _solar_power_plant [last update 8 July 2017 ].

[13]S.Stark ."This hybrid power plant combines 3 clean energy sources in one," Energy.Gov Newsletters

Available: http://energy.gov/articles/hybrid-powerplant-combines-3-clean-energy-sources-one [Oct. 19, 2016].

[14]T. Tsanova. "To-the-point: 50-MW CSP park produces 1st power in China," News-Renewables Available:

http://renewables.seenews.com/news/to-thepoint-50-mw-csp-park-produces-1st-power-inchina-544154\# [Oct. 24, 2016].

[15]M. Fawer and B. Magyar "Solar industry Entering new dimensions" Bank Sarasin \& Cie AG Eds.

Available:http://www.esocialsciences.org/Downlo $\mathrm{ad} /$ repecDownload.aspx?fname=Document 11012 2010400.3811609. pdf\&fcategory=Articles\&Ald $=3$ 298\&fref=repec [Novembre 2010].

[16]IEA, Technology Roadmap 2014 Technology Roadmap: Solar Photovoltaic Energy - 2014 edition https://www.iea.org/publications/freepublications/ publication/technology-roadmap-solarphotovoltaic-energy---2014-edition.html [September 2014]. 
[17] Fraunhofer Project: Middle East and North Africa Region Assessment of the Local Manufacturing Potential for Concentrated Solar Power (CSP) Projects

Available:

https://www.ise.fraunhofer.de/en/researchprojects/assessment-the-local-manufacturingpotential-of-csp [December 2010]

[18] ANEST Associazione Nazionale Energia Solare Termodinamica (in Italian)

Available: http://anest-italia.it/wpcontent/uploads/2014/03/Presentazione-ANESTGennaio-2014.pdf [January. 2014].

[19]ESTELA European Solar Thermal Electricity Association, Press Release "How solar thermal electricity creates jobs and improves energy security in Europe," Available: $\quad$ http://www.estelasolar.org/wpcontent/uploads/2015/11/2015.03.17-PressRESTELA-Position-Paper-

Final.pdf?x66361 [March, 2015].

[20] MESIA-Middle East Solar Industry Association: "Middle East Solar Outlook for 2016," Available: http://www.mesia.com/wpcontent/uploads/MESIA-Outlook-2016-web.pdf [January 2016].
[21] "Renewable energy in the water, energy \& food nexus,"- International Renewable Energy Agency (IRENA) report Available: http://www.irena.org/DocumentDownloads/Public ations/IRENA_Water_Energy_Food_Nexus_2015 .pdf [January 2015].

[22] Various authors (2014): "Moving forward for an ageing society: Bridging the distances," Italian position paper.

ISBN 978-88-6060-649-5.

Available:

http://attiministeriali.miur.it/media/246231/moving _forward_for_an_ageing_society.pdf [November 2014].

[23] Lighting Africa - Benefits of Off-Grid Solar Products Available: https://www.lightingafrica.org/about/why-off-gridenergy/ [in progress]. 